\title{
Breast Cancer Awareness: Survey of Participants at Annual Walk in Kigali
}

Joy Bahumura ${ }^{1 *}$, Josephine Murekezi ${ }^{2}$, Ruth Sego ${ }^{1,3}$, Richard Nsengiyumva ${ }^{1}$, Pamela Meharry ${ }^{1,4}$

1. School of Nursing and Midwifery, College of Medicine and Health Sciences, University of Rwanda

2. Rwanda Association of Midwives, Kigali, Rwanda

3. New York University, New York, US

4. University of Illinois, Chicago, Illinois, US

*Corresponding author: Joy Bahumura (jbahumura@yahoo.fr)

\begin{abstract}
Background: Breast cancer is the leading cause of cancer death in low-income countries and the second leading cause in high-income countries. Most women in sub-Saharan Africa are diagnosed later, with limited access to timely and effective treatment. Objectives: The main objective was to identify the awareness of breast cancer warning signs among participants attending the 2016 Breast Cancer Awareness Walk. Methods: A cross-sectional study of 93 participants was conducted after the Annual Breast Cancer Awareness Walk in Kigali on 23 October 2016. Participants, 15 years or older, completed the survey. Data were analyzed using descriptive statistics and Chi-square test. Results: The breast cancer warning sign "breast lump" was identified by over half of the women (54\%) and many men (41\%), though the majority $(70 \%)$ did not know that the lump could be painless. The majority of participants were unaware of the many other breast cancer signs, and that the risk increases with age. Three potential barriers to delay seeking healthcare for a serious breast problem included lack of insurance or money to pay, difficulty to make appointment with doctor, and fear of removal of breast. Conclusion: Increased public awareness and early detection is imperative to help reduce the morbidity and mortality related to breast cancer in Rwandan women and men.
\end{abstract}

Keywords: Breast cancer awareness, warning signs, age-related risk, breast checking, delays to care, sub-Saharan Africa, women's health

\section{Background}

Globally, breast cancer is the most common cancer to afflict women. It is the leading cause of cancer death in low-income countries and the second leading cause in high-income countries.[1] Most women in high-income countries are diagnosed at an earlier and localized stage (I and II), whereas most women in low-and-middleincome countries (LMIC) are diagnosed at a later stage with advanced disease (III and IV).[2] The five-year survival rate for breast cancers diagnosed in late stage is $24 \%$, compared to $80-90 \%$ with early stage breast cancers in high-income countries.[3] Awareness of breast cancer warning signs, monthly breast checking, and accessing healthcare earlier could all contribute to optimal outcomes for African women.

The incidence of breast cancer globally in 2012 was 1.67 million cases, with regional rates varying widely from 27 per 100,000 in Central Africa, to 92 per 100,000 in Northern America, according to the latest
GLOBOCAN report from the International Agency for Research on Cancer (IARC).[1] In Africa, the estimated incidence per 100,000 women reveal rates of 26.8 in Central Africa, 30.4 in East Africa, 38.6 in West Africa, and 38.9 in Southern Africa.[1] Breast cancer was the most common cancer diagnosis reported to the Rwanda Biomedical Center during the 2007 to 2013 period, with $15.8 \%$ of people affected.[4]

A systematic review of sub-Saharan African countries, showed that breast cancer is diagnosed at later stages and earlier ages, specifically 10-15 years younger than highincome countries.[5] A delayed breast cancer diagnosis is likely to lead to more advanced stage cancer in LMIC, and due to either patient and/or system delays.[2,6] In Rwanda, Pace and colleagues recently discovered that the median delay to treatment was 15 months and delays of $\geq 6$ months were significantly associated with more advanced-stage cancer. [6] Over the past two decades, several older studies documented an early-age onset of breast cancer in Africa, [7] which provides support for 
recent findings in Rwanda indicating the median age of 49 years at time of diagnosis.[6] In the US, the median age is 62 years and less than five percent are diagnosed younger than 40 years of age.[8]

The risk of developing breast cancer is 1 in 9 for women and 1 in 1,000 for men in the United States. [9] The etiology of the disease is unknown, though the cell's DNA becomes damaged due to genetic or environmental factors, or a combination of the two. Since men develop breast cells and tissue they are also at risk for breast cancer. Though their risk is very low, men's mortality rate is higher than women due to the misperception that it is not likely breast cancer and attendant delay of diagnosis and treatment. $[9,10]$

The incidence of breast cancer is likely to increase further in LIMC as the population lives longer and increased urbanization leads to more people adopting unhealthy Western lifestyles.[11] The World Health Organization states a key strategy to control breast cancer is raising the general public awareness.[12] The purpose of this study was to survey breast cancer awareness among women and men at the Breast Cancer Awareness Walk in Kigali, October 23, 2016. Specific objectives included awareness of warning signs, agerelated risk, frequency of women performing self-breast exams, and assessment of potential reasons for delaying access to care for a serious breast problem.

\section{Methods}

This was a convenience sample of those attending the 2016 Ulinzi Walk, the Annual Breast Cancer Awareness Walk in Kigali, the capital city of Rwanda. The Breast Cancer Initiative East Africa (BCIEA) has organized the annual walk in Kigali since 2012. According to the founder Philippa Kibugu, the aim of the breast cancer walk was to increase "awareness, education and empowerment." Specific objectives for the study participants included: to recognize warning signs of breast cancer; to determine age-related risk; to identify frequency of self-breast exams (for women), and to consider potential reasons to delay seeking healthcare for a breast problem.

After an explanation of the study and written consent, the study participants completed a two-page selfadministered survey. There was a survey for women and a survey for men with similar questions. Both the consent and survey were available in Kinyarwanda and English, depending on the participant's preference. A total of 93 participants were recruited and completed the survey. The response rate was high; almost all potential study participants approached by data collectors consented to be in the study.

Data on women's awareness were collected using the
Breast Cancer Awareness Measure (Breast-CAM), a valid and reliable instrument developed by Cancer Research UK, King's College London and University College London.[13] Linsell and colleagues reported that the Breast-CAM was specifically designed to measure breast cancer awareness. [14] The two-page survey consisted of 11 questions: demographic characteristics, awareness of breast cancer warning signs, age-related risk, frequency of self-breast exam, reasons to delay seeking health care services, and family and personal history of breast cancer. The survey was adapted for use in Rwanda using the official guidelines to maintain specific breast cancer awareness questions and rearrangement of questions for sensitivity purposes. For example, placement of the question, Have you ever had breast cancer near the end of the survey, instead of at the beginning where it might upset the participant and prevent completion of the survey.

Data on men's awareness were collected using a survey developed from the current literature on breast cancer symptoms in men, as we were unable to find a preexisting survey. Researcher Dr. Lindsay Forbes had documented that they intended to develop a men's survey, but contact with her directly on October 11, 2016, revealed that had not been done yet. We therefore developed the Breast-MAN, also an 11-question, two-page survey that included similar questions to the Breast-CAM, such as the socio-demographic characteristics, knowledge on breast cancer, and health care seeking behavior. However, we did exclude the question: How often do you examine your breasts, as that is not evidenced-based practice for men yet. Also, we removed the question: Would your husband delay you seeking care.

Our data collectors, registered midwives and nurses, approached women and men congregated in the hall after the walk, to be included in the study. The surveys were anonymous and coded with a study number. There was no monetary compensation for completing the survey. Data were analyzed using descriptive statistics and Chi-square test in SPSS Version 24.

The outcome measures were primarily based on the response to three awareness questions: Identify five or more warning signs; A 70-year-old woman most at risk; and Self-reported checking of breasts once a week or once a month. The outcome measures for the original British BREAST-CAM criteria used the combined score of the three awareness questions; however, their target population was cognizant of common breast cancer symptoms from years of educational campaigns with the National Health Service (NHS). The Rwanda population is not that familiar with breast cancer symptoms, so Dr Forbes, who was part of the original British study, advised us to analyze the questions separately (email communication, Oct 11, 2016). 
Permission to conduct the study was obtained from the University of Rwanda Institutional Review Board, and the organizers of the East Africa Breast Cancer Alliance. Informed consent was sought from all participants prior to data collection. The forms were collected with only a study number and no personal identifying information. Results were reported in aggregate form.

\section{Results}

The study's demographic characteristics were presented (see Table1). Of the 93 study participants, most $(76.3 \%$ ) were women and nearly a quarter were men (23.7\%). The age range was 15-66 years, with a mean age of 38 years. Over half of the women (54.9\%) stated Kinyarwanda was there primary language and about a third (35.2\%) stated English. Three quarters of the men's primary language was Kinyarwanda and a few (13.6\%) used English. The majority of those participating had a university degree; with women (53.5\%) and men $(45.5 \%)$.

Women and men were surveyed for a medical history and/or family history of breast cancer. Fourteen women $(19.7 \%)$ and one man $(4.5 \%)$ had a family history. Six women $(8.5 \%)$ and one man $(4.5 \%)$ had a history of breast cancer. Some participants were unsure of their family history or refused to respond to the question.

Table 1

Demographic Characteristics

\begin{tabular}{lll}
\hline & $\begin{array}{c}\text { Women } \\
\mathbf{n ~ ( \% )} \\
71(76.3 \%)\end{array}$ & $\begin{array}{c}\text { Men } \\
\mathbf{n ~ ( \% )}\end{array}$ \\
& & $22(23.7 \%)$ \\
\hline Age (years) & $23(32.4 \%)$ & $14(63.7 \%)$ \\
$\leq 30$ & $20(28.2 \%)$ & $3(13.6 \%)$ \\
$31-40$ & $11(15.5 \%)$ & $4(18.2 \%)$ \\
$41-49$ & $13(18.3 \%)$ & $0(\%)$ \\
$50-59$ & $4(5.6 \%)$ & $1(4.5 \%)$ \\
$\geq 60$ & $39(54.9 \%)$ & $17(77.3 \%)$ \\
Primary language & $25(35.2 \%)$ & $3(13.7 \%)$ \\
Kinyarwanda & $5(7.1 \%)$ & $1(4.5 \%)$ \\
English & $2(2.8 \%)$ & $1(4.5 \%)$ \\
French & $1(1.4 \%)$ & $0(0 \%)$ \\
Swahili & $7(9.9 \%)$ & $4(18.2 \%)$ \\
Highest level of education & $24(33.8 \%)$ & $8(36.4 \%)$ \\
None & $38(53.5 \%)$ & $10(45.4 \%)$ \\
Primary & $1(1.4 \%)$ & $0(0 \%)$ \\
Secondary & $6(8.5 \%)$ & $1(4.5 \%)$ \\
University & & \\
Practical course & & $1(4.5 \%)$ \\
Breast Cancer history & $14(19.7 \%)$ & $17(77.3 \%)$ \\
Family history & $44(62 \%)$ & $1(4.5 \%)$ \\
Yes & $10(14.1 \%)$ & $3(13.7 \%)$ \\
No & $3(4.2 \%)$ & \\
Unsure or don't know & & \\
Refused & & \\
& &
\end{tabular}


Women and men were asked about their awareness of breast cancer and the findings are presented (Table 2). The majority of women $(66 \%)$ stated that they were aware of some of the warning signs of breast cancer and half $(50 \%)$ of men. Over half of women (53.5\%) knew that a lump was a warning sign of breast cancer, though only a little over a quarter $(29.6 \%)$ knew the lump could be painless. Many of the men (40.9\%) knew a lump was a warning sign and over a quarter $(27.3 \%)$ knew it could be painless. However, the majority of women and men were not aware of other warning signs, with responses ranging from the lowest awareness of the warning sign nipple rash (only $9.9 \%$ for women) to the highest awareness of the warning sign pain in breast/ armpit (31.8\% for men).

Table 2

Participants' awareness of breast cancer warning signs, age-related risk, and frequency of
breast checking*

\begin{tabular}{|c|c|c|c|c|}
\hline & \multicolumn{2}{|c|}{$\begin{array}{c}\text { Women } \\
\mathbf{n}(\%) \\
71(76.3 \%)\end{array}$} & \multicolumn{2}{|c|}{$\begin{array}{c}\text { Men } \\
\mathbf{n}(\mathbf{0}) \\
22(23.7 \%)\end{array}$} \\
\hline & Yes & No* & Yes & No* \\
\hline \multicolumn{5}{|l|}{ Aware of Warning signs } \\
\hline Lump in breast & $38(53.5 \%)$ & $33(46.5 \%)$ & $9(40.9 \%)$ & $13(59.1 \%)$ \\
\hline Lump in armpit & $21(29.6 \%)$ & $50(70.4 \%)$ & $5(22.7 \%)$ & $17(77.3 \%)$ \\
\hline Lump is painless & $21(29.6 \%)$ & $50(70.4 \%)$ & $6(27.3 \%)$ & $16(72.7 \%)$ \\
\hline Pain in breast/armpit & $19(26.8 \%)$ & $52(73.2 \%)$ & $7(31.8 \%)$ & $15(68.2 \%)$ \\
\hline Puckering/dimpling & $20(28.2 \%)$ & $51(71.8 \%)$ & $5(22.7 \%)$ & $17(77.3 \%)$ \\
\hline Redness of skin & $17(23.9 \%)$ & $54(76.1 \%)$ & $4(18.2 \%)$ & $18(81.8 \%)$ \\
\hline Nipple retraction & $8(11.3 \%)$ & $63(88.7 \%)$ & $4(18.2 \%)$ & $18(81.8 \%)$ \\
\hline Nipple rash & $7(9.9 \%)$ & $64(90.1 \%)$ & $5(22.7 \%)$ & $17(77.3 \%)$ \\
\hline Nipple discharge & $16(22.5 \%)$ & $55(77.5 \%)$ & $6(27.3 \%)$ & $16(72.7 \%)$ \\
\hline Change in nipple position & $15(21.1 \%)$ & $56(78.9 \%)$ & $3(13.6 \%)$ & $19(86.4 \%)$ \\
\hline Change in breast size & $18(25.4 \%)$ & $53(74.6 \%)$ & $6(27.3 \%)$ & $16(72.7 \%)$ \\
\hline Change in breast/nipple shape & $17(23.9 \%)$ & $54(76.1 \%)$ & $6(27.3 \%)$ & $16(72.7 \%)$ \\
\hline \multicolumn{5}{|l|}{ Aware of Age-related risk } \\
\hline 30-year-old & $11(15.5 \%)$ & $60(84.5 \%)$ & $0(0 \%)$ & 0 \\
\hline 50-year-old & $7(9.9 \%)$ & $64(90.1 \%)$ & $0(0 \%)$ & 0 \\
\hline 70-year-old & $1(1.4 \%)$ & $70(98.6 \%)$ & $0(0 \%)$ & 0 \\
\hline At any age & $35(49.3 \%)$ & $36(50.7 \%)$ & $11(50 \%)$ & $11(50 \%)$ \\
\hline Do not know or did not respond & $17(23.9 \%)$ & $54(76.1 \%)$ & $11(50 \%)$ & $11(50 \%)$ \\
\hline
\end{tabular}

\section{Aware of Breast checking**}

At least once a month

$11(15.5 \%) \quad 60(84.5 \%)$

At least once a week

$7(9.9 \%)$

$64(90.1 \%)$

Do it, don't know how often

$13(18.3 \%)$

$58(81.7 \%)$

Rarely

$16(22.5 \%)$

$55(77.5 \%)$

Never

$16(22.5 \%)$

$55(77.5 \%)$

Did not respond

$8(11.3 \%)$

$63(88.7 \%)$

* No or no answer

**Breast checking - only women surveyed, based on evidenced-based practice recommendation

Nearly all women (98.6\%) and men (100\%) did not know that the risk of breast cancer increases with age. Only one woman knew that a 70 -year old is more at risk. About half of the women (49.3\%) and men (50\%) surveyed thought that they were at risk of breast cancer at any age. Less than than a quarter of women $(23.9 \%)$ and half of men (50\%) did not know, or did not respond, to the age-related risk question.

Results of how often a woman checks her breasts for cancer showed that a quarter of women are aware to check their breasts monthly (15.5\%) or weekly (9.9\%). 
Other women do it, don't know how often (18.3\%), or rarely $(22.5 \%)$. A third of those surveyed never check their breasts or did not respond to the question.

Participants were asked potential reasons why they may delay seeking healthcare for a serious breast symptom. The women's responses are presented (Table 3). The three main reasons why women would often or sometimes delay healthcare included lack of insurance or money to pay (45\%), difficult to make appointment with doctor $(42 \%)$, and fear of removal of breast $(42 \%)$. The three main reasons why men would delay seeking healthcare for a potential serious breast symptom include lack of insurance or money to pay (36.4\%), wait a while hoping the problem would go away (36.3\%), and too many other things to worry about $(31.8 \%)$.

Table 3

Potential reasons why women may delay seeking healthcare for perceived breast problem

\begin{tabular}{|c|c|c|c|c|}
\hline Reasons & $\begin{array}{l}\text { Yes } \\
\text { (often) } \\
\mathrm{n}(\%)\end{array}$ & $\begin{array}{c}\text { Yes } \\
\text { (sometimes) } \\
\mathrm{n}(\%)\end{array}$ & $\begin{array}{l}\text { No } \\
\text { n }(\%)\end{array}$ & $\begin{array}{l}\text { Do not know } \\
\text { n }(\%)\end{array}$ \\
\hline Visit the traditional healer first & $4(6 \%)$ & $6(9 \%)$ & $40(56 \%)$ & $7(10 \%)$ \\
\hline $\begin{array}{l}\text { Wait a while; hoping the problem } \\
\text { would go away }\end{array}$ & $13(18 \%)$ & $15(21 \%)$ & $32(45 \%)$ & 0 \\
\hline Wait until it becomes more a problem & $9(13 \%)$ & $13(18 \%)$ & $39(55 \%)$ & 0 \\
\hline Too scared to go and see the doctor & $12(17 \%)$ & $12(17 \%)$ & $35(49 \%)$ & 0 \\
\hline Fear of removal of breast by surgery & $15(21 \%)$ & $15(21 \%)$ & $28(39 \%)$ & $1(1 \%)$ \\
\hline Lack of insurance or money to pay & $12(17 \%)$ & $20(28 \%)$ & $27(38 \%)$ & $1(1 \%)$ \\
\hline $\begin{array}{l}\text { Difficult to make appointment } \\
\text { with doctor }\end{array}$ & $10(14 \%)$ & $20(28 \%)$ & $30(42 \%)$ & $1(1 \%)$ \\
\hline Too busy to make time to go to doctor & $5(7 \%)$ & $18(25 \%)$ & $35(49 \%)$ & 0 \\
\hline Too many other things to worry about & $10(14 \%)$ & $11(16 \%)$ & $34(48 \%)$ & $3(4 \%)$ \\
\hline $\begin{array}{l}\text { Not feeling confident talking about my } \\
\text { symptoms with doctor }\end{array}$ & $5(7 \%)$ & $6(9 \%)$ & $47(66 \%)$ & 0 \\
\hline Worrying about what doctor might find & $7(10 \%)$ & $12(17 \%)$ & $39(55 \%)$ & $2(3 \%)$ \\
\hline Husband may not agree & $4(6 \%)$ & $1(1 \%)$ & $46(65 \%)$ & $3(4 \%)$ \\
\hline Difficult to arrange transport & $6(9 \%)$ & $19(27 \%)$ & $34(48 \%)$ & 0 \\
\hline Too embarrassed to go and see doctor & $2(3 \%)$ & $5 \quad(7 \%)$ & $49(69 \%)$ & 0 \\
\hline My doctor is difficult to talk to & $1(1 \%)$ & $6 \quad(9 \%)$ & $47(66 \%)$ & $2(3 \%)$ \\
\hline
\end{tabular}

*Not everyone answered every question, so the number of participants does not equal the total sample size of 93.

Study participants were also given the chance to write additional information in the comments sections. There were 17 comments and the majority stated that lack of money or insurance would delay seeking healthcare.

A crosstabs analysis was conducted to determine potential correlations using Chi-square in SPSS. There were no significant differences in awareness of warning signs related to education $\left(\chi^{2}=5.331, \mathrm{df}=4 \mathrm{p}=.255\right)$, family history $\left(\chi^{2}=.368, \mathrm{df}=1 \mathrm{p}=.544\right)$, or personal history of breast cancer $\left(\chi^{2}=1.254\right.$, df $\left.=3 \mathrm{p}=.740\right)$. There were also no significant differences between women's and men's awareness of warning signs $\left(\chi^{2}=\right.$ $1.877, \mathrm{df}=1 \mathrm{p}=.171)$, or awareness of advancing age as a risk factor $\left(\chi^{2}=6.720, \mathrm{df}=4 \mathrm{p}=.151\right)$. The third measure of breast cancer awareness was breast checking and since that is not yet an evidenced-based practice for men we did not include that question in the study.

\section{Discussion}

The breast cancer awareness survey is a quick and easy tool to survey women at the annual Breast Cancer Awareness Walk in Kigali. The response rate was high and all women $(n=71)$ and men $(n=22)$ completed the survey in less than 10 minutes. The results indicate that the awareness of breast cancer in this population is fairly low and there is no statistical significance between variables using Chi Square.

There was a wide age range (15-66 years) of participants who completed the Walk and survey. The majority indicated Kinyarwanda (60\%) and English (30\%) are the primary languages spoken, and some identified with French (6.5\%) and Swahili (3.2\%). Based on the level of education, the majority of respondents completed university or secondary levels. This information is 
important for planning purposes to design messages and materials that could potentially increase breast cancer awareness in Rwanda.

Breast cancer awareness was low among the women and men participating in the study. Most respondents had no medical history or family history of breast cancer. Based on the combined scoring of the three specific questions validating awareness by British standards, no participants were able to answer all three awareness questions correctly. For this reason, we chose to analyze the questions independently and included all of the warning symptoms, including the lump and pain symptoms, as many women in Rwanda are not aware that these may indicate breast cancer. These symptoms are typically excluded in other studies, such as those conducted in developed countries, as they are considered common knowledge.[14]

\section{Warning signs}

A quarter of the participants (24.7\%) in the study were aware of five or more warning signs, which is an indication of breast cancer awareness. The majority of women (53.5\%) and nearly half the men (40.9\%) surveyed were aware that a lump is a warning sign, which is the most common symptom of breast cancer(15). However, nearly three quarters of the women $(70.4 \%)$ and men $(72.7 \%)$ did not know that the lump is often painless.

In a systematic review of 42 studies by Khan and colleagues (2015) in Malaysia, limited knowledge of breast cancer caused misconceptions and delays in accessing healthcare.[16] Ten women in our study $(15 \%)$ said they would visit the traditional healer first, which would delay seeking care at a health facility. In Kenya, oncologists visited traditional healers to advise that women with breast problems should be referred to physicians immediately to improve their chance of survival. If women and men are aware of breast cancer symptoms, they are better able to make an informed decision as to whether to seek healthcare or not.

\section{Age-related risk}

The strongest risk factor for breast cancer is advancing age. Although breast cancer is more common after menopause in developed countries, [1] breast cancer is likely to affect women at an earlier age in developing countries. $[2,5,6]$

Only one woman (1.07\%) in our study was aware that a 70-year-old woman (or older) is at a greater risk compared to a 30-year-old, 50-year-year old, or a woman at any age. The majority of women (49.3\%) thought that women at any age were at risk, and about a quarter $(23.9 \%)$ did not know or did not respond. However, the age-related risk needs further explanation. Women in
Africa appear to get breast cancer at an earlier age, as many are diagnosed between $40-50$ years, $[6,7]$ unlike in the US, where most women are diagnosed between age 60-70 years. [17] Therefore, women in Africa need to be alerted that they are at risk during their reproductive years and a clinical breast check should be performed during antenatal care and postnatal care when women are likely to assess the health centers and hospitals for healthcare.

\section{Breast checking}

Most breast cancers develop slowly over time and are typically not fatal when discovered early in the disease. A quarter of the women in the study $(25.3 \%)$ met the criteria for breast cancer awareness by checking their breasts either weekly or monthly. However, the majority $(56.3 \%)$ responded that they never or rarely check their breasts, or they did not respond to the question. This finding is supported in the literature by Tetteh and Faulkner who reported that the practice of breast selfexamination among women in sub-Saharan Africa is “poor".[18]

In a systemic review by Khan and colleagues, women thought that a self-breast exam prevented cancer, when in fact it only aids in an earlier diagnosis.[16] Efforts to detect and diagnose breast cancer earlier have not been successful due to limited knowledge of the public and a significant number of cases being diagnosed late in Stage III and IV.[18] In another recent review, O'Mahony and colleagues demonstrated a significant improvement in breast cancer awareness at one-month post intervention compared to the control group. [19] A monthly breast check can contribute to early detection of breast problems and timely treatment. There is a big knowledge gap among women in Rwanda, which requires an immediate educational intervention that is context specific. [20,21]

\section{Potential reasons to delay seeking healthcare}

Reasons why women would delay seeking healthcare for a potential serious breast symptom ranged from a high concern for lack of insurance or money to pay (45\%) to a low concern, husband may not agree (7\%). Hypothetically, many thought it would be difficult to make an appointment $(42 \%)$, feared removal of breast $(42 \%)$, wait a while hoping the problem would go away (39\%), difficult to arrange transport $(36 \%)$, too scared to see the doctor $(34 \%)$, too busy $(32 \%)$, and visiting the traditional healer first $(15 \%)$. Men were also most concerned about money $(36.4 \%)$, would wait a while hoping it would go away $(36.4 \%)$, or had too many other things to worry about $(31.8 \%)$.

We choose a healthy population to study breast cancer awareness, as women with breast cancer may have 
different perceptions, attitudes, and knowledge,[22] but we found that was not the case. Some of the main concerns in our study identifying hypothetical delays were actual delays of 15 months for women with breast problems in a recent study in $\mathrm{R}$ wanda. Pace and colleagues interviewed and reviewed the medical records of the 144 women who were attending two rural hospitals for breast complaints.[6] The four main reasons for patient delay in Pace's study included; the patient was not bothered by the problem at first $(76 \%)$, thought the problem would go away (63\%), visited the traditional healer first $(21 \%)$ and thought treatment would be too expensive $(14 \%)$. The mean age of the women was 49 years and $76 \%$ were in stage III or IV, meaning the breast cancer had already spread to the lymph nodes and therefore able to metastasize to any part of the body. To help reduce delays, the authors recommended educating communities to promote earlier detection of breast cancer in women of reproductive age.

Odongo and colleagues found the median delay was 13 months in a cross-sectional study of 162 patients in Uganda and likely related to women with limited social support.[23]The authors stated that women who are knowledgeable of breast cancer are more likely to come in earlier as they are aware of the seriousness of the symptom. Sharma and colleagues identified lower income and educational level caused delays in accessing healthcare in a systematic review that included Ghana and Nigeria.[24] The authors recommended increased breast cancer awareness and access to affordable healthcare. Brinton and colleagues conducted a literature review on breast cancer in sub-Saharan Africa[25] and concluded that there is a need to understand the reasons for delaying access to care, identify the etiological factors that are preventable, and provide educational campaigns to increase early detection and therefore earlier intervention.

The present study did have some limitations. We used a convenience sample from a limited population at the Ulinzi Walk; therefore it cannot be generalized. The sample size was small, though nearly half of the Walk participants completed the survey. Translation from English to Kinyarwanda posed a problem as some of the questions lost their original meaning. For example, "breast lump" is an easy concept to understand in the English language, but there is no easy translation into Kinyarwanda, the nearest association being "breast abscess.' The survey was conducted after a fivekilometer walk, so some of the respondents may have been tired and had difficulty trying to concentrate.

Based on our study findings, breast cancer awareness needs to go beyond the Ulinzi Walk in October to other days and months throughout the year and other communities across Rwanda. Breast cancer is the most significant cancer for women in Africa and the WHO recommends advocating for policies and programmes, including means to control it, in addition to raising public awareness.[12] O'Mahony and colleagues reported in a Cochrane Review that a randomized control trial demonstrated a brief intervention may increase awareness, though the authors recommended additional research using large sample size, longitudinal design, and validated outcome measures.[19]

This study should be repeated at the Ulinzi Walk annually to detect trends in the population attending the Walk. The BREAST-CAM survey should also be extended to include other communities, particularly different rural community settings to better advocate for them in breast cancer awareness campaigns. The survey could also be used at the University of Rwanda to test and raise the awareness of all students and faculty in all disciplines.

\section{Conclusion}

Findings from the survey reveal that many of the participants attending the 2016 Breast Cancer Awareness Walk correctly identified "breast lump" as a warning sign of breast cancer, though the majority was unaware of other breast cancer signs. It is therefore important to increase awareness and education as women and men aware of breast cancer symptoms would seek healthcare sooner, which would reduce delays and the attendant late-stage diagnosis. Policy makers need to be aware that early detection through increased public awareness would improve the breast cancer outcome and survival of women, and even men, in Rwanda.

\section{References}

1. Ferlay J, Soerjomataram I, Dikshit R, Eser S, Mathers C, Rebelo M, et al. Cancer incidence and mortality worldwide: Sources, methods and major patterns in GLOBOCAN 2012. Int J Cancer. 2015;136(5):E359-86.

2. Unger-Saldaña $\mathrm{K}$. Challenges to the early diagnosis and treatment of breast cancer in developing countries. World J Clin Oncol. 2014;5(3):465.

3. World Cancer Research Fund International. Breast cancer statistics |World Cancer Research Fund International. 2015.

4. Ministry of Health R. Rwandans urged on early cancer detection. 2015;

5. Jedy-Agba E, McCormack V, Adebamowo C, dos-SantosSilva I. Stage at diagnosis of breast cancer in sub-Saharan Africa: a systematic review and meta-analysis. Lancet Glob Heal. 2016;4(12):e923-35.

6. Pace LE, Mpunga T, Hategekimana V, Dusengimana J-M V., Habineza H, Bigirimana JB, et al. Delays in breast cancer presentation and diagnosis at two rural cancer 
Referral Centers in Rwanda. Oncologist. 2015;20(7):780-8.

7. Vanderpuye V, Grover S, Hammad N, PoojaPrabhakar, Simonds H, Olopade F, et al. An update on the management of breast cancer in Africa. Infect Agent Cancer. 2017;12(1):13.

8. Howlader N, Noone A, Krapcho M, Miller D. SEER Cancer Statistics Review 1975-2013 National Cancer Institute SEER Cancer Statistics Review 1975-2013 National Cancer Institute. 2016. p. 1992-2013.

9. BreastCancer.org. U . S . Breast Cancer Statistics. 2017. p. 1-2.

10. New Times. VIDEO : Male breast cancer : I ignored the swelling on my breast. 2017. p. 1-4.

11. Akarolo-Anthony SN, Ogundiran TO, Adebamowo CA, Farmer P, Frenk J, Knaul F, et al. Emerging breast cancer epidemic: evidence from Africa. Breast Cancer Res. 2010;12(Suppl 4):1-4.

12. World Health Organization. Cancer Breast cancer : prevention and control. 2014. p. 11-3.

13. Cancer Research UK. Cancer Awareness Measure (CAM) Toolkit (version 2). 2008. p. 1-82.

14. Linsell L, Forbes LJL, Burgess C, Kapari M, Thurnham A, Ramirez AJ. Validation of a measurement tool to assess awareness of breast cancer. Eur J Cancer. 2010;46(8):1374-81.

15. ACS - American Cancer Society. Breast Cancer Signs and Symptoms. Breast Cancer. 2017;1-3.

16. Khan, Leong, Ming H. Association of Knowledge and Cultural Perceptions of Malaysian women with delay in diagnosis and treatment of breast cancer: a Systematic Review. Asian Pac J Cancer Prev. 2015;16(13):5349-57.

17. American Cancer Society. What are the key statistics about breast cancer? Cancer.org. 2014;1-2.
18. Tetteh D, Faulkner S. Sociocultural factors and breast cancer in sub-Saharan Africa: implications for diagnosis and management. Women's Heal. 2016;12(1):147-56.

19. O’Mahony M, Comber H, Fitzgerald T, Corrigan MA, Fitzgerald E, Grunfeld EA, et al. Interventions for raising breast cancer awareness in women. Cochrane Database Syst Rev. 2017;2017(2).

20. Yip CH, Smith RA, Anderson BO, Miller AB, Thomas DB, Ang ES, et al. Guideline implementation for breast healthcare in low- and middle-income countries: Early detection resource allocation. Cancer. 2008;113(8 SUPPL.):2244-56.

21. Anderson BO, Cazap E, El Saghir NS, Yip C-H, Khaled HM, Otero I V, et al. Optimisation of breast cancer management in low-resource and middle-resource countries: executive summary of the Breast Health Global Initiative consensus, 2010. Lancet Oncol. 2011 Apr;12(4):387-98.

22. Montazeri A, Vahdaninia M, Harirchi I, Harirchi AM, Sajadian A, Khaleghi F, et al. Breast cancer in Iran: need for greater women awareness of warning signs and effective screening methods. Asia Pac Fam Med. 2008;7(1):6.

23. Odongo J, Makumbi T, Kalungi S, Galukande M. Patient delay factors in women presenting with breast cancer in a low income country. BMC Res Notes. 2015;8(1):467.

24. Sharma K, Costas A, Shulman LN, Meara JG. A systematic review of barriers to breast cancer care in developing countries resulting in delayed patient presentation. J Oncol. 2012;2012.

25. Brinton LA, Figueroa JD, Awuah B, Yarney J, Wiafe S. NIH Public Access. Breast Cancer Res. 2015;144(3):46778. 